\title{
Vulnerabilidade e Vigilância em Regiões Socioassistenciais de Santa Catarina: uma avaliação da política pública no âmbito da assistência social
}

\author{
Paloma Mariucci ${ }^{1}$ \\ Silvio Antônio Ferraz Cario ${ }^{2}$
}

\section{RESUMO}

No processo de desenvolvimento sustentado, o território se apresenta como um espaço de integração de políticas, programas, projetos e formação do cidadão, situando-se como elemento fundamental nos novos desenhos das políticas públicas. A Assistência Social, vista como política pública, possibilita a gestão dos serviços conforme demandas e potencialidades da população, e incorpora o debate sobre proteção social ao se pensar estratégias de gestão, com foco no combate à pobreza e à exclusão social e territorial. Nesse sentido, este artigo tem como objetivo contribuir com elementos para a identificação do território como uma unidade essencial para se pensar a efetivação do acesso à proteção social, por meio dos serviços socioassistenciais, possibilitando a proximidade do poder público nessas áreas. Para tanto, realiza-se pesquisa empírica e bibliográfica que, através do levantamento de informações do Cadastro Único, quantifica a população em situação de vulnerabilidade e risco social em Santa Catarina. Os resultados contribuem no planejamento de ações, com vistas a garantir estratégias de intervenção na realidade. Em importância, os resultados percebidos em nível regional evidenciam números expressivos da população em vulnerabilidade social e extrema pobreza no estado catarinense, principalmente nas regiões Oeste, Serrana e Planalto Norte.

Palavras-chave: território; vulnerabilidade; vigilância socioassistencial; políticas públicas.

\section{ABSTRACT}

In the processs of sustained development, the territory presentes itself as a space for the integration of policies, programs, projetcts and the formation of citzens, standing as a fundamental element in the new designs of public policies. Social Assistance, seen as a public policy, enables the management os services according to the demands and potencial of the population, and incorporates the discussion on social protection when thinking about management strategies, with a focus on combating poverty and social and territorial exclusion. In this sense, this articles aims to contribute with elements for the identification of the territory as an essencial unit to think about the effetctive access to social protection, through social assistance services, allowing the proximity of the public power in these áreas. For this purpose, realize empirical and bibliographic research, colleting information from the Single Registry, quantifies the population in situations of vulnerability and social risk in Santa Catarina. The results contribute to planning of actions, with a view to ensuring intervetion strategies in reality. In importance, the results perceived at the regional level showing significant number of population in social vulnerability and extreme poverty in state of Santa Catarina, especially in West, Mountain and Higland North regions.

Keyword: territory, vulnerability, socio-assistance surveillance; public policy.

\section{INTRODUÇÃO}

No âmbito da Política Pública de Assistência Social, a questão da dimensão territorial assume cada vez mais relevância. Compreender o território e suas dinâmicas é inseri-lo como fator estratégico

\footnotetext{
${ }^{1}$ Assistente Social, Especialista em Sustentabilidade, Desenvolvimento e Gestão de Projetos Sociais. Mestranda do Programa de Pós-Graduação em Administração da Universidade Federal de Santa Catarina (PPGA/UFSC). Email palomamariucci@yahoo.com.br

2 Mestre em Economia pela Universidade Federal do Rio Grande do Sul (UFRGS) e Doutor em Ciências Econômicas pela Universidade Estadual de Campinas (UNICAMP). Professor Titular da Universidade Federal de Santa Catarina (UFSC).
} 
para a organização da política pública, dado que é no espaço territorial que se encontram os variados grupos sociais em situações de vulnerabilidade e risco social.

A territorialização, compreendida sob a lógica da localização e da proximidade, evidencia que os serviços sociais, ao serem implementados próximos ao cidadão, podem antecipar respostas às suas necessidades e facilitar o acesso a seus direitos, em uma perspectiva de proteção social proativa. Tais serviços podem também compreender e mensurar riscos e vulnerabilidades do território, assim como intervir na realidade através do planejamento de ações de prevenção e redução desses agravos.

Os diferentes espaços se tornam campo para a atuação profissional, visto que é onde os problemas se manifestam, onde as pessoas vivem e se reproduzem, e onde é possível priorizar e articular ações governamentais. Além disso, são valorizadas as dimensões regionais, nos processos geradores de exclusão, e a territorialidade como variáveis relevantes no combate à pobreza e às desigualdades sociais.

Nesses termos, para o amadurecimento da assistência social como política pública setorial, torna-se crucial considerar o território no desenvolvimento de capacidades de planejamento e gestão. Assim, os processos de produção, análise e utilização de informações, considerando o espaço territorial, ganham relevância na medida em que possibilitam qualificar a intervenção dos agentes públicos, de forma que suas ações gerem resultados mais condizentes com as expectativas e necessidades da população.

Considerando esse referencial, o conceito de territorialidade, utilizado na relação com a gestão social, vai além daquele meramente geográfico (que estabelece um espaço único), para abranger uma concepção muito mais ampla (como local vivido). Para tanto, o novo paradigma da gestão social, voltada para descentralização, se complementa no aspecto da territorialidade, e estabelece que o seu objeto de atuação seja uma população determinada, percebida social e territorialmente.

No atual estágio de desenvolvimento do Sistema Único de Assistência Social (SUAS), tornamse cada vez mais visíveis os desafios referentes ao fortalecimento da gestão e qualificação dos serviços; sendo que o enfrentamento desses desafios pressupõe o conhecimento de "onde estão e quantos são" os que demandam por proteção social e "qual é a capacidade dos equipamentos e serviços para suprir suas necessidades".

Nessa perspectiva, o conceito de vigilância social, apresentado pela Política Nacional de Assistência Social (PNAS) e pelo SUAS, é tratado como estratégico para o conhecimento da realidade socioterritorial, servindo de subsídios para o desenvolvimento de ações com vistas à proteção social. Ganha destaque o Centro de Referência da Assistência Social (CRAS), com base nos princípios de descentralização, de superação da fragmentação das ações e de busca pela universalização da cobertura, sendo uma forma de o poder público se fazer presente nos territórios considerados vulneráveis, ganhando sentido na vida da população.

Considera-se que os serviços socioassistenciais, ofertados nos CRAS, inserem a valorização e a importância do fortalecimento do território, pensado como localização e como elemento essencial para 
a efetivação do acesso à proteção social, possibilitando, com isso, uma proximidade entre o poder público e a população. Com essas considerações, o presente estudo tem como objetivo realizar uma análise situacional das vulnerabilidades constituídas nas regiões socioassistenciais do estado de Santa Catarina, e evidenciar que a Assistência Social, através dos seus equipamentos de proteção social, especificamente os 378 CRAS implantados, atua com grande relevância na prevenção das situações de risco por meio do desenvolvimento de potencialidades, no fortalecimento de vínculos familiares e comunitários e na ampliação do acesso aos direitos de cidadania.

Para tanto, encontra-se estruturado em sete seções, incluindo esta primeira onde se faz a introdução; na segunda seção, são discutidos elementos teóricos, analíticos e institucionais referentes ao tema tratado; na terceira, trata-se da institucionalidade criada para combater a vulnerabilidade social; na quarta, da metodologia; na quinta, apresentam-se os resultados para, na sexta, apontarem-se as políticas públicas desenvolvidas; e, por fim, a conclusão, exposta na sétima seção.

\section{TRATAMENTO TEÓRICO-ANALÍTICO}

\subsection{Estado, Desenvolvimento e Funções}

No campo da Economia, existem duas grandes perspectivas analíticas sobre a atuação do Estado na promoção do desenvolvimento. Uma advoga menor intervenção, e a outra traça papel ativo do Estado, observando-se que essas perspectivas, liberal e desenvolvimentista, se contrapõem entre si. A primeira prega o livre mercado, em que forças de oferta e demanda devem ser a primazia, devendo, com isso, ocorrer mínima intervenção do Estado na economia. Essa concepção conduz, segundo seus idealizadores, a eficiência econômica, gerando, por consequência, bem-estar coletivo. Neste quadro, o Estado deve atuar de modo pontual; apenas para corrigir falhas de mercado, uma vez sanadas, deve-se retirar e deixar que o mercado por si só promova o desenvolvimento. Além desta intervenção pontual, compete ao Estado, ainda, regular mercados não competitivos, ofertar bens públicos e controlar externalidades negativas.

A segunda visão, desenvolvimentista, por seu turno, considera que o desenvolvimento econômico precisa ser provocado, planejado e orientado pelo Estado. Segundo essa visão, o mecanismo de mercado não garante o desenvolvimento, pois o mercado expressa uma determinada estrutura de poder e tem como objetivo o lucro empresarial individual. O desenvolvimento, contudo, deve ter como objeto a nação, o coletivo e o futuro da sociedade. Nesse sentido, deve-se pautar por um projeto deliberado ou estratégico, em intervenção consciente, com respaldo social e político de segmentos e classes da sociedade (FONSECA, 2014). Nesse campo, Bresser Pereira (2007, p. 280) aponta que o desenvolvimento tem como instrumento fundamental "[...] o próprio Estado, dada sua capacidade de definir normas, estabelecer políticas e, com sua capacidade administrativa e financeira, implementálas". 
Considerando essa segunda perspectiva como determinante para promover o desenvolvimento, Iglésias (2010) lista diversas funções que, desde fins do século XX e início do século XXI, o Estado deve assumir, a saber: $1^{\circ}$.) lograr um Estado capaz de tornar viável a eficiência do mercado, a concorrência e a regulação; $2^{\circ}$.) tornar o Estado impulsionador da capacidade produtiva - políticas para setores prioritários; $3^{\circ}$.) fazer um Estado com responsabilidade de diminuir a desigualdade social; $4^{\circ}$.) implementar novo relacionamento do Estado com a empresa privada, pautado por cooperação; $5^{\circ}$.) desenvolver ações do Estado para maior participação da sociedade civil nas funções estatais; $6^{\circ}$.) orientar e formular políticas de inserção internacional - integração nos mercados regional e mundial; $7^{\circ}$.) apoiar o desenvolvimento da inovação tecnológica através da extensão e qualidade da educação; $8^{\circ}$.) fortalecer a capacidade de análise sobre tendências da economia, da sociedade e da política em âmbito internacional; $9^{\circ}$.) desenvolver a capacidade do Estado fazer planejamento de ações estratégicas de desenvolvimento de longo prazo; e, $10^{\circ}$.) promover consensos econômicos e sociais nacionais em torno do Estado, empresa privada e sociedade civil.

Em complemento, Chang (1999), fazendo severa crítica aos defensores da minimização do papel do Estado na economia, sem negar a importância do mercado, ressalta que este é apenas uma instituição dentre outras na promoção do desenvolvimento. É o Estado que disciplina, através do estabelecimento de normas, regras, leis etc., o comportamento humano na sociedade, sem retirar do capitalismo características marcantes da propriedade privada, da liberdade individual e da concorrência de mercado. Considerando essa linha de interpretação, o autor aponta cinco funções do Estado desenvolvimentista: $1^{\circ}$.) ter como objetivo o crescimento de longo prazo; $2^{\circ}$.) traçar o planejamento estratégico; $3^{\circ}$.) propor a mudança estrutural; $4^{\circ}$.) administrar os conflitos de interesse; e, $5^{\circ}$.) apresentar perspectiva nacionalista. No capitalismo, cabe ao Estado papel de realizar planejamento de longo prazo, no sentido de definir horizontes a serem alcançados, considerando as mudanças estruturais - tecnológicas, institucionais e organizacionais - que ocorrem sistematicamente, além dos diversos conflitos de interesses reinantes numa sociedade composta de classes sociais distintas (CHANG, 1999).

Bresser Pereira (1997) ressalta que o Estado passa por transformações ao longo do tempo, em linha com as mudanças que ocorrem nas organizações produtivas capitalistas. No imediato pós II Guerra Mundial, 1939-1945, até o final dos anos 1970, o Estado figurou como desenvolvimentista, sendo grande responsável pelas taxas significativas de crescimento econômico. Porém, no curso dos anos 1980 e parte dos anos 1990, as crises fiscal e financeira do Estado somadas ao esgotamento do paradigma fordista de produção - queda da taxa de lucro, esgotamento do ciclo inovativo, acirramento do conflito capital e trabalho entre os outros motivos, o Estado entrou em crise. Nesse mesmo período, emerge a reforma do Estado, a partir das diretrizes do Consenso de Washington, orientando as ações governamentais dos países capitalistas. No curso da segunda metade dos anos 1990 e nas primeiras décadas dos anos 2000, conjugam-se novas funções do Estado, a saber: $1^{\text {a }}$.) programas de privatização; $2^{\mathrm{a}}$.) terceirização e publicização dos serviços sociais; $3^{\mathrm{a}}$.) programas de desregulação e de aumento dos 
mecanismos de controle; $4^{\mathrm{a}}$.) aumento da governança do Estado com reforma administrativa; e, $5^{\mathrm{a}}$.) aumento da governabilidade - instituições políticas que garantam a melhor intermediação dos interesses e tornem os governos mais democráticos.

Em linha com esta argumentação, somam-se os resultados de diversos estudos demonstrando que o Estado se constitui ator estratégico na construção da trajetória de desenvolvimento capitalista dos países adiantados e retardatários (CHANG, 2000; GERSCHENKRON, 1962). No exercício desta função, a participação esteve condicionada ao ambiente histórico, econômico e social, cuja heterogeneidade institucional proporciona distintas forma de participação estatal (ZYSMAN, 1994). Contudo, no conjunto, tal consideração vai ao encontro dos escritos de Braudel (1996) reforçando que o capitalismo só triunfa quando se identifica com o Estado, pois este cria condições e instrumentos para o desenvolvimento, de forma ampliada, do capital.

É consensual, nos dias atuais, que, com a globalização, considerada o estágio mais elevado do desenvolvimento capitalista, com presença de investimentos transfronteiras e acirramento da concorrência mundial, esteja ocorrendo a perda de autonomia nacional. As novas regras de competição - abertura de mercado, desregulamentação econômica, livre fluxo de capitais etc. - reduzem a capacidade doméstica de fazer política. No entanto, em contraponto, com essas regras, reforça-se a importância do Estado na elaboração de uma estratégica nacional de desenvolvimento, pois assim, não só empresas capitalistas competem, mas Estados Nação também passam a concorrer entre si, no propósito de ter uma participação ativa na divisão internacional do trabalho e na apropriação do excedente capitalista gerado mundialmente.

Nesses termos, não sem razão, é que Bresser Pereira (2007, p. 280) destaca a necessidade de o Estado ser o condutor de uma estratégia de desenvolvimento nacional. Desse modo, afirma que: “A liderança cabe ao governo e aos membros mais ativos da sociedade civil. Seu instrumento é o próprio Estado, dada sua capacidade de definir normas, estabelecer políticas e, com sua capacidade administrativa e financeira, implementá-las” (BRESSER PEREIRA, 2007, p. 280).

No âmbito do Estado, em tempos recentes, figura nova forma de gestão pública denominada de governança pública, a qual não ignora alguns elementos característicos dos modelos de gestão anteriores, como patrimonialista, burocrático e gerencialista. Por outro lado, traz também novos elementos característicos, que permitem intervenção multidimensional: Estado, Sociedade e Mercado. Nas decisões, as intervenções envolvem não só o mercado, mas também a sociedade. Assim, os projetos de governo devem ser tratados como de Estado, contudo devem ser instituídos para e com a sociedade. Dias (2012) e Dias e Cario (2014) apresentam as características principais da gestão estatal, sob o signo da governança pública, traduzidas em: eficiência e eficácia administrativa; equidade social e responsividade - administrar o público para o público; relação aberta com o ambiente, poder descentralizado; coordenação de processos cooperativos e de redes; aceitação de participação de outros 
atores; adoção de mecanismos de democracia representativa e direta; e manutenção das funções de controle e planejamento.

Nesses termos, a gestão estatal, sob a matriz da governa pública, deve se instrumentalizar para acompanhar os resultados das ações desenvolvidas em linha com os objetivos, as diretrizes e as ações estratégicas estabelecidas, objetivando alcançar a visão de futuro desejada. Nesse processo, torna-se fundamental contar com indicadores e metas que articulem os desenhos dos planos de curto e médio prazo com os planos de longo prazo. Para tanto, definir os indicadores, bem como acompanhá-los e melhorá-los no curso do processo de desenvolvimento constituem ações importantes, para o bom desempenho da gestão pública na sociedade.

\subsection{Vulnerabilidade, Vigilância Socioassistencial e Território}

Esses três conceitos se relacionam, sendo que a vulnerabilidade compreende situações ou identidades que podem levar à exclusão social dos sujeitos - situações as quais têm origem no processo de produção e reprodução de desigualdades sociais e de processos discriminatórios e segregacionistas. A vulnerabilidade não se restringe à questão financeira; ela envolve a relação entre direitos e rede de serviços, e entre políticas públicas e a capacidade dos indivíduos ou grupos sociais de acessar esse conjunto de bens e serviços, de modo a exercer a sua cidadania (BRASIL, 2004).

O enfoque da vulnerabilidade e dos riscos, ao evidenciar as diferentes estratégias que devem ser desenvolvidas para fazer frente a riscos específicos e fortalecer a capacidade de resposta das famílias para a redução de sua vulnerabilidade, permite uma ligação mais próxima com o campo das políticas públicas.

Os grupos que convivem nestes locais estão constantemente sob os mais diversos riscos, como fome, mortalidade infantil e violência, associadas, de forma direta, aos fatores de vulnerabilidade, como baixa renda familiar, condições precárias de domicílio, baixo nível de escolaridade, além do próprio lugar onde vivem, que também se constitui em fator de vulnerabilidade (BUSS, 2007; MARICATO, 2001; TORRES et al., 2003).

Desse modo, para enfrentar a vulnerabilidade, é fundamental considerar a ideia da vigilância socioassistencial e de direitos socioassistenciais, os quais encontram-se vinculados à assistência social, que promove a defesa e a proteção social, com foco em seu caráter preventivo e de preservação, extrapolando a dimensão individual. Logo, a vigilância socioassistencial apresenta caráter compensatório e aponta o vínculo da assistência social com a realidade, firmando-se como prática de política correspondente ao dever do Estado e direito do cidadão à proteção social (BRASIL, 2013).

Para tanto, compete à vigilância socioassistencial saber onde estão e quantos são os que demandam por proteção social, bem como reconhecer a capacidade dos equipamentos e serviços para 
suprir suas necessidades. Assim, a produção de informações a partir da demanda e da oferta dos serviços, vista na perspectiva do território, constitui-se um dos eixos da vigilância socioassistencial.

Nesse caso, a vigilância refere-se ao ato ou ao resultado de um indivíduo ou um grupo estar em um estado de alerta permanente. No caso da assistência social, significa que os responsáveis devem estar atentos, com vistas a identificar a vulnerabilidade como aspecto social, e detectar e informar as características e dimensões das situações de precarização que vulnerabilizam e trazem riscos e danos aos cidadãos, a sua autonomia, à socialização e ao convívio familiar (BRASIL, 2012).

A vigilância jamais deve ser compreendida e executada como ferramenta de coerção e controle da população; ou como instrumento do Estado para vigiar, enquadrar e punir cidadãos. $\mathrm{O}$ uso da palavra vigilância, na expressão vigilância socioassistencial, adotada pela política de assistência social, pode conduzir a equívocos, tendo em vista que a assistência social foi construída, historicamente, permeada pelo caráter do não direito, dirigida aos pobres, a quem o Estado deveria controlar e não proteger (SILVA, 2012).

Destarte, é a partir da vigilância socioassistencial que se podem produzir, sistematizar, analisar e disseminar informações, acerca "das situações de vulnerabilidade e risco que incidem sobre famílias e indivíduos e dos eventos de violação de direitos em determinados territórios, e do tipo, volume e padrões de qualidade dos serviços ofertados pela rede socioassistencial” (BRASIL, 2012).

Essa prerrogativa torna a função de vigilância socioassistencial uma ponte fundamental, que garantirá, através de estudos e produtos, o conhecimento das demandas sociais e do ordenamento da oferta de serviços socioassistenciais. Assim, deve trabalhar tanto em prol da confecção de diagnósticos do território e da população, evidenciando as vulnerabilidades e riscos desses territórios e indivíduos, quanto diagnosticar a realidade da oferta dos serviços de assistência social, podendo instrumentalizar os gestores com informações e dados, a partir da realidade local (BRASIL, 2013).

Nessa perspectiva, a vigilância socioassistencial deve se preocupa com o território e as populações que ali habitam e reproduzem seu modo de vida, ou seja, com o uso do território e das relações que as populações estabelecem com o meio e entre si (SANTOS, 1994, 1996, 2000). Assume, como princípio básico, o olhar coletivo e não individual, permitindo, ainda, que a Assistência Social forneça tratamento individualizado para cada caso, visto que a Política social não se pauta na abordagem individual.

Torna-se imperioso, para tanto, que a vigilância socioassistencial recorra ao planejamento, à produção, organização e sistematização de informações sobre a realidade socioterritorial, buscando, com isso, identificar situações de vulnerabilidades e riscos pessoal e social de famílias e indivíduos (BRASIL, 2012). Afirma-se, desse modo, a necessidade de conhecimento do território, das populações vulneráveis e das demandas pelos serviços da Assistência Social.

Assim sendo, a perspectiva da dimensão territorial se faz imprescindível. Para Couto, Yazbek e Raichelis (2010, p. 50), “o território é o terreno das políticas públicas, onde se concretizam as 
manifestações da questão social e se criam os tensionamentos e as possibilidades para seu enfrentamento". É no território, pelas questões de proximidade e de identidade cultural, que acontecem as relações sociais mais identificadas com as reais demandas por direitos, serviços e benefícios sociais. É nesses espaços que também são produzidas as necessidades dos cidadãos, como moradia, transporte, educação, saúde, saneamento e tantas outras.

Esse enfrentamento de questões sociais trouxe novas demandas para a Assistência Social, entre elas a importância de se conhecer melhor os territórios, identificando, assim, as possíveis vulnerabilidades e riscos, bem como as necessidades por serviços socioassistenciais. Para identificar a instalação de serviços socioassistenciais nos territórios vulneráveis, é necessário identificar os riscos das famílias que ali vivem para, então, organizar serviços e programas de prevenção, evitando que se instalem, ou, no caso de já terem provocado agravos ou sequelas individuais e sociais, atenuá-los.

Nesse sentido, as políticas sociais decorrentes devem ser percebidas e instrumentalizadas como demandas coletivas, ressaltando-se que, para serem atendidas, exigem-se ações e planejamento do governo. Uma atividade de planejamento governamental depende desse reconhecimento, por meio da elaboração de diagnósticos que levem em consideração as particularidades locais de diferentes regiões, a fim de que se conheça a real demanda de proteção social dos cidadãos, segundo suas características.

\section{ASSISTÊNCIA SOCIAL: o Arcabouço Institucional e o Centro de Referência de Assistência Social}

Segundo a Lei Orgânica da Assistência Social - LOAS/1993, a Assistência Social é definida e faz parte da Política de Seguridade Social. Trata-se, portanto, de uma Política de Proteção Social. Nesse sentido, deve-se entender proteção social como os instrumentos que uma sociedade constitui para proteger os cidadãos dessa mesma sociedade, seja por ocorrência natural ou social, como velhice, enfermidades, miséria ou privações (BRASIL, 1993, 2004). Para tanto, a proteção social deve trabalhar com vistas a assegurar condições de vida digna para a população, procurando garantir a cidadania. Deve proporcionar segurança para sobrevivência, além de acolhida e convivência familiar (BRASIL, 2004).

Sob essa visão, a Assistência Social quebra o antigo rótulo de que ela sustenta uma relação clientelista, assistencialista e filantrópica (CF/1988; LOAS/1993), estabelecendo uma nova relação de proteção social, de afirmação de direitos, garantia de condições e, ainda, modificando o seu públicoalvo, que deixa se ser apenas os pobres e carentes, para envolver toda e qualquer população que esteja em situação de riscos e vulnerabilidades (MESTRINER, 2001; SPOSATI, 2004).

A prevenção e a promoção social buscam o fortalecimento de vínculos, com ampliação de direitos, estratégias da proteção básica, que podem ser percebidas na conceituação do CRAS, estabelecida nas Orientações Técnicas do Centro de Referência de Assistência Social:

O CRAS é uma unidade de proteção social básica do SUAS, que tem por objetivo prevenir a ocorrência de situações de vulnerabilidades e riscos sociais nos territórios, por meio do desenvolvimento de potencialidades e aquisições, do fortalecimento de

Revista Desenvolvimento Socioeconômico em debate v.6 n.2 (2020) 
vínculos familiares e comunitários, e da ampliação do acesso aos direitos de cidadania (BRASIL, 2009).

Segundo definição do Ministério de Desenvolvimento Social (MDS), embasada na PNAS/2004, o CRAS é uma unidade pública da Política de Assistência Social, de base municipal, integrante do SUAS, localizado em áreas com maiores índices de vulnerabilidade e risco social. Destinam-se esses Centros à prestação de serviços e programas socioassistenciais de proteção social básica às famílias e indivíduos e à articulação destes serviços no seu território de abrangência, em uma atuação intersetorial com a perspectiva de potencializar a proteção social. Trata-se de um equipamento público fundamental, que tem por fim garantir os direitos sociais, de maneira descentralizada, como unidade de possibilidades de acesso aos direitos de proteção social e de efetivação da cidadania, e como referência no atendimento da população local, reconhecendo os diferentes processos que, em múltiplas escalas, ali se cruzam (BRASIL, 2004).

As ações públicas da área da assistência social, destacando-se as desenvolvidas nos CRAS, devem ser, segundo a Norma Operacional Básica (NOBSUAS), planejadas territorialmente, tendo em vista a superação de sua fragmentação, o alcance da universalidade de cobertura, a possibilidade de planejamento e monitoração da rede de serviços e a realização da vigilância social das exclusões e estigmatizações presentes nos territórios de maior incidência de vulnerabilidade (BRASIL, 2008).

Considerando esses aspetos, o estado de Santa Catarina, localizado na região Sul do Brasil, contempla 295 municípios e população estimada, em 2017, de 7.001.161 habitantes (IBGE 2018). De acordo com os dados divulgados pelo Atlas do Desenvolvimento Humano no Brasil - 2013, Santa Catarina situa-se dentro de uma faixa de desenvolvimento humano considerada alta pelo Programa das Nações Unidas para o Desenvolvimento (PNUD). De acordo com a publicação, em 2010, o estado atingiu um Índice de Desenvolvimento Humano (IDH) de 0,774, o terceiro maior do país, atrás somente do Distrito Federal e do estado de São Paulo.

Contudo, muito embora desfrute de uma situação privilegiada quanto ao IDH, Santa Catarina contempla grandes contrastes em relação à vulnerabilidade e pobreza de seus municípios, coexistindo índices considerados alto, médios e aqueles muito baixos. Segundo dados da Secretaria de Estado da Assistência Social, Trabalho e Habitação, há, atualmente, em Santa Catarina, 466.213 pessoas em situação de pobreza e extrema pobreza, ou seja, com renda per capita inferior a R \$170,00.

É certo que o fator econômico influencia os índices de vulnerabilidades de cada população, verificando-se regiões econômicas mais desenvolvidas que outras no estado. Nesse sentido, como cada região tem suas especificidades e particularidades e cada município possui estruturas, realidades, dimensões territoriais e populacionais distintas, as situações de risco e vulnerabilidade ocorrem de forma bastante diferenciada.

Dessa forma, os CRAS, se apresentam como uma unidade pública estatal, descentralizada da política de assistência social, responsável pela organização e oferta de serviços de proteção social básica 
do Sistema Único de Assistência Social (SUAS), nas áreas de vulnerabilidade e risco social dos municípios. Dada sua capilaridade nos territórios, o CRAS se caracteriza como a principal porta de entrada às ações do SUAS, ou seja, é uma unidade que possibilita o acesso de um grande número de famílias à rede de proteção social de assistência social.

Os 378 CRAS existentes no estado (CADSUAS, 2018) assumem, como fatores identitários, dois grandes eixos estruturantes do Sistema Único de Assistência Social - SUAS: a matricialidade sociofamiliar e a territorialização. O SUAS, ao eleger a matricialidade sociofamiliar como uma de suas bases estruturantes, organiza toda a rede socioassistencial para o apoio às famílias, a fim de assegurar a toda a população o direito à convivência familiar, seguindo o pressuposto de que, para a família prevenir, proteger e manter seus membros, é necessária a ação efetiva do poder público. O CRAS, assim, considera as famílias como um espaço de ressonância e sinergia dos interesses e necessidades coletivas e de mobilização à participação e ao protagonismo social, ou seja, como um vetor de mudança da realidade social.

\section{PROCEDIMENTOS METODOLÓGICOS}

Com o objetivo de compreender melhor a questão da vulnerabilidade no estado de Santa Catarina, é fundamental reconhecer as condições sociais de carência material das famílias, e reconhecer nelas as características que as tornam fragilizadas, seja de ordem econômica, de gênero, de ciclos de vida ou de incapacidade.

Com a preocupação de abordar de uma maneira mais completa não somente a pobreza, mas também as diversas modalidades da desvantagem social, foram utilizadas, neste estudo, informações do Cadastro Único para Programas Sociais - CADUNICO. Esse Cadastro constitui um instrumento de identificação e caracterização socioeconômica das famílias brasileiras de baixa renda, isto é, que têm renda mensal de até meio salário mínimo por pessoa; ou renda mensal familiar total de até três salários mínimos.

As informações utilizadas neste estudo provêm da Base do Cadastro Único, Versão 7/ abril de 2018, a qual reúne informações dos domicílios e de cada um dos membros da família, permitindo avaliar tanto as condições de vida de cada família quanto as do conjunto da população cadastrada no estado.

É no município que se inicia a construção da base de dados do Cadastro Único. Nele que são identificadas as famílias que possuem perfil para o cadastramento e são coletadas e digitadas as informações na base nacional. A partir desse registro, as pessoas recebem o Número de Identificação Social (NIS), que as identifica no Cadastro Único.

Em 2005, a NOB/SUAS elencou as variáveis que definem a população vulnerável como o conjunto de pessoas residentes, que apresentem pelo menos uma das características relacionadas a seguir:

Revista Desenvolvimento Socioeconômico em debate v.6 n.2 (2020) 
1. Famílias com serviços de infraestrutura inadequados:

1.1. Abastecimento de água proveniente de poço, nascente ou outra forma

1.2. Sem banheiro ou sanitário

1.3. Destino do lixo inadequado, conforme legislação

1.4. Mais de dois moradores por dormitório

2. Famílias com renda familiar per capita inferior $1 / 4$ salário mínimo

3. Família com renda familiar per capita inferior $1 \frac{1}{2}$ salário mínimo:

3.1. Com pessoas de 0 a 14 anos

3.2. Com responsável com menos de quatro anos de estudo

4. Família com chefe de família mulher, sem cônjuge:

4.1. Com filhos menores de 15 anos

4.2. Analfabeta

5. Família com uma pessoa com 16 anos ou mais:

5.1. Desocupada (procurando trabalho)

5.2. Com quatro ou menos anos de estudo

6. Família com uma pessoa de 10 a 15 anos, que trabalha

7. Família com uma pessoa de 4 a 14 anos, que não estuda

8. Família com renda familiar per capita inferior a $1 \frac{1}{2}$ salário mínimo:

8.1. Com pessoa com deficiência

8.2. Com pessoa de 60 anos ou mais

As informações apresentadas na sequência englobam o levantamento de algumas das dimensões apresentadas. Nesse sentido, foram destacadas as seguintes variáveis: renda familiar per capita; características dos domicílios - espécie de domicílio, abastecimento de água, existência de banheiro, forma de coleta de lixo e tipo de iluminação -; nível educacional; e tipo de trabalho. Os dados provenientes de CADUNICO foram analisados considerando oito regiões do estado, que congregam 295 municípios, assim expressas: Grande Oeste, Meio Oeste, Planalto Norte, Foz do Rio Itajaí Nordeste, Vale do Itajaí. Grande Florianópolis, da Serra, e Sul, conforme a Figura 1.

Figura 1: Macrorregiões e regiões socioassistenciais de Santa Catarina, 2015.

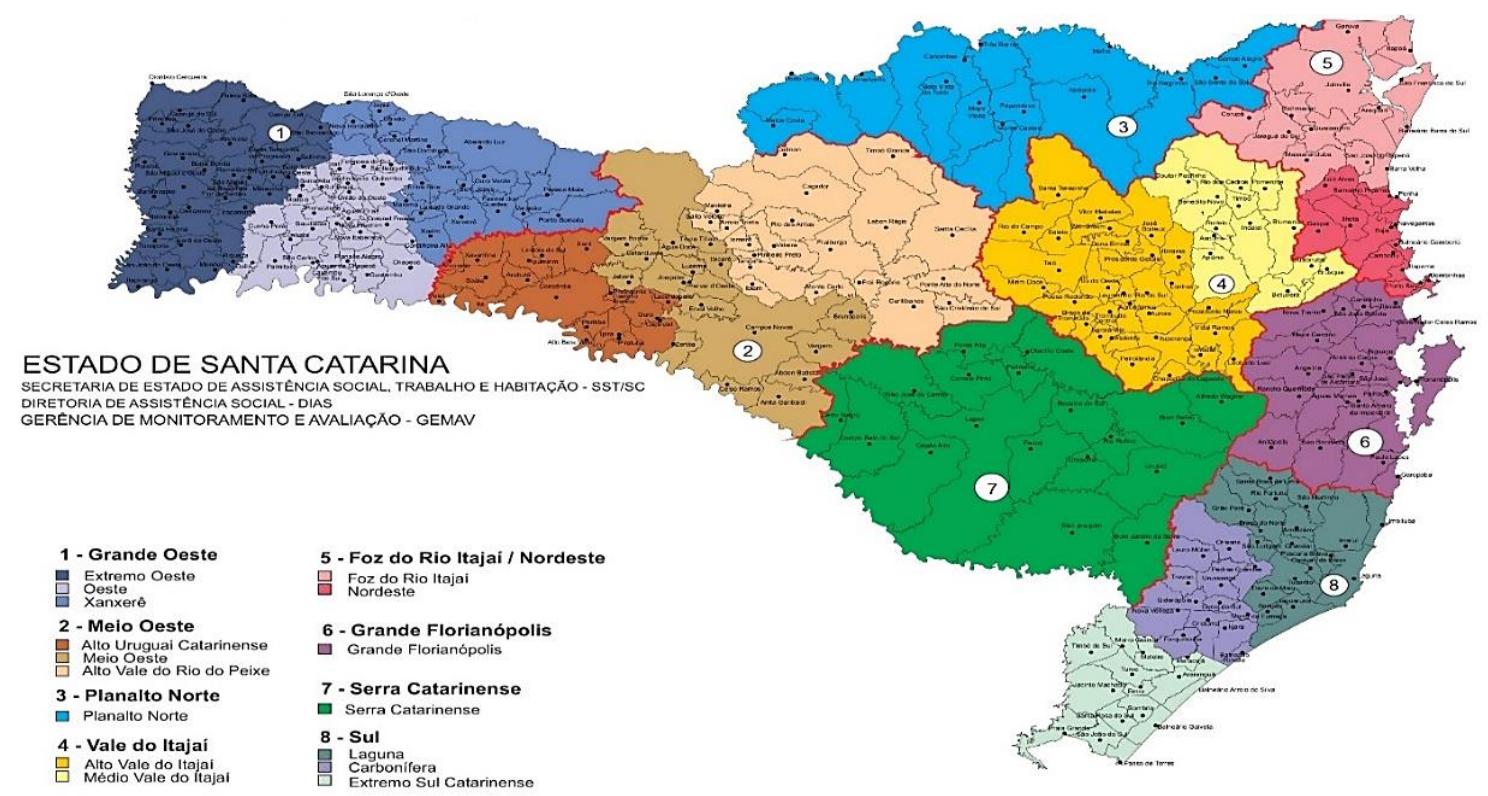

Fonte: Elaboração própria 


\section{RESULTADOS}

A Assistência Social como política de proteção social visa garantir, sem contribuição prévia, a provisão dessa proteção a todos que dela necessitam, significando aportar quem, quantos, quais e onde estão os brasileiros demandatários de serviços e atenções de assistência social. Nesse sentido, a situação atual para a construção da política pública de assistência social precisa levar em conta três vertentes de proteção social: as pessoas, as suas circunstâncias, e, dentre elas, seu núcleo de apoio primeiro, isto é, a família. A proteção social exige a capacidade de maior aproximação do cotidiano da vida das pessoas, pois é nele que riscos e vulnerabilidades se constituem (BRASIL, 2004).

Ao agir nas capilaridades dos territórios e se confrontar com a dinâmica do real, no campo das informações, essa política inaugura outra perspectiva de análise ao tornar visíveis aqueles setores da sociedade brasileira, tradicionalmente tidos como invisíveis ou excluídos das estatísticas (BRASIL 2004).

Algumas das principais características que marcam o estado de vulnerabilidade social são as condições precárias de moradia e saneamento, os meios de subsistência inexistentes e a ausência de um ambiente familiar, por exemplo. Tais fatores compõem o estágio de risco social; quando o indivíduo deixa de ter condições de usufruir dos mesmos direitos e deveres dos outros cidadãos, dado o desequilíbrio socioeconômico instaurado.

Nessa via, tendo como base as informações do Cadastro Único cabe reconhecer indicadores de vulnerabilidade e risco em curso, nas Regiões Socioassistenciais de Santa Catarina.

Tabela 1: Quantitativos absolutos e percentuais de famílias cadastradas no Cadastro Único em abril/2018 e total dos domicílios nas regiões socioassistenciais de Santa Catarina, 2010

\begin{tabular}{lccc}
\hline \multicolumn{1}{c}{ Região } & $\begin{array}{c}\text { Total de Famílias } \\
\text { (domicílios) no CadÚnico }\end{array}$ & $\begin{array}{c}\text { Percentual de famílias } \\
\text { (domicílios) no CadÚnico }\end{array}$ & $\begin{array}{c}\text { Total de domicílios } \\
\text { (IBGE 2010) }\end{array}$ \\
\hline Grande Oeste & 55.715 & $22,01 \%$ & 253.089 \\
Meio Oeste & 50.274 & $23,15 \%$ & 217.117 \\
Planalto Norte & 25.207 & $20,18 \%$ & 124.853 \\
Foz Rio Itajaí Nordeste & 76.551 & $12,35 \%$ & 619.587 \\
Vale do Itajaí & 34.385 & $11,05 \%$ & 310.925 \\
Grande Florianópolis & 55.451 & $13,03 \%$ & 425.562 \\
Serra & 30.134 & $28,31 \%$ & 106.429 \\
Sul & 52.637 & $14,21 \%$ & 370.370 \\
Total & 380.354 & $15,66 \%$ & 2.427 .932 \\
\hline
\end{tabular}

Fonte: CADUNICO - abril/2018 
Segundo registra-se na Tabela 1, constata-se a existência, em 2010, de 2,4 milhões de domicílios em Santa Catarina. Em abril de 2018, o registro era de 380,3 mil famílias. As três regiões que apresentaram maiores percentuais de famílias nesse Cadastro foram, pela ordem: Serra $(28,31 \%)$, Meio Oeste $(23,15 \%)$ e Grande Oeste $(22,01 \%)$.

No estado de Santa Catarina, existiam 1.090.435 pessoas (380.354 famílias) no Cadastro Único, representando 15,57\% da população de 7,0 milhões de pessoas, em abril de 2018, conforme expõe-se na Tabela 2, a seguir. Destas famílias, a maioria encontrava-se na região da Serra Catarinense, seguida pelas regiões do Meio Oeste, Planalto Norte e Grande Oeste, expressando inscrições, nesse Cadastro, acima da média nacional. Tais regiões abrangiam, cada uma, mais de $20 \%$ de famílias inseridas, o que indica um número significativo de famílias de baixa renda e/ou em vulnerabilidade nestes locais, conforme, ilustra-se, na sequência, no Gráfico 1.

Tabela 2: Quantitativos absolutos e percentuais de pessoas cadastradas no cadastro único e estimativa populacional nas regiões socioassistenciais de Santa Catarina, abril/2018.

\begin{tabular}{lccc}
\hline \multicolumn{1}{c}{ Região } & $\begin{array}{c}\text { Total de Pessoas cadastradas } \\
\text { no Cadastro Único }\end{array}$ & $\begin{array}{c}\text { Percentual de pessoas } \\
\text { no Cadastro Único }\end{array}$ & $\begin{array}{c}\text { Estimativa } \\
\text { População2017 (IBGE) }\end{array}$ \\
\hline Grande Oeste & 159.509 & $20,30 \%$ & 785.733 \\
Meio Oeste & 140.865 & $22,18 \%$ & 635.179 \\
Planalto Norte & 77.311 & $20,42 \%$ & 378.604 \\
Foz do Rio Itajaí Nordeste & 219.301 & $12,48 \%$ & 1.757 .892 \\
Vale do Itajaí & 102.213 & $9,69 \%$ & 1.054 .838 \\
Grande Florianópolis & 154.881 & $13,36 \%$ & 1.158 .976 \\
Serra & 85.437 & $29,23 \%$ & 292.243 \\
Sul & 150.918 & $16,09 \%$ & 937.696 \\
Total & 1.090 .435 & $15,57 \%$ & 7.001 .161 \\
\hline
\end{tabular}

Fonte: CADUNICO - abril/2018

Gráfico 1: Percentual de famílias e de pessoas no Cadastro Único nas Regiões Socioassistenciais de Santa Catarina, abril/2018.

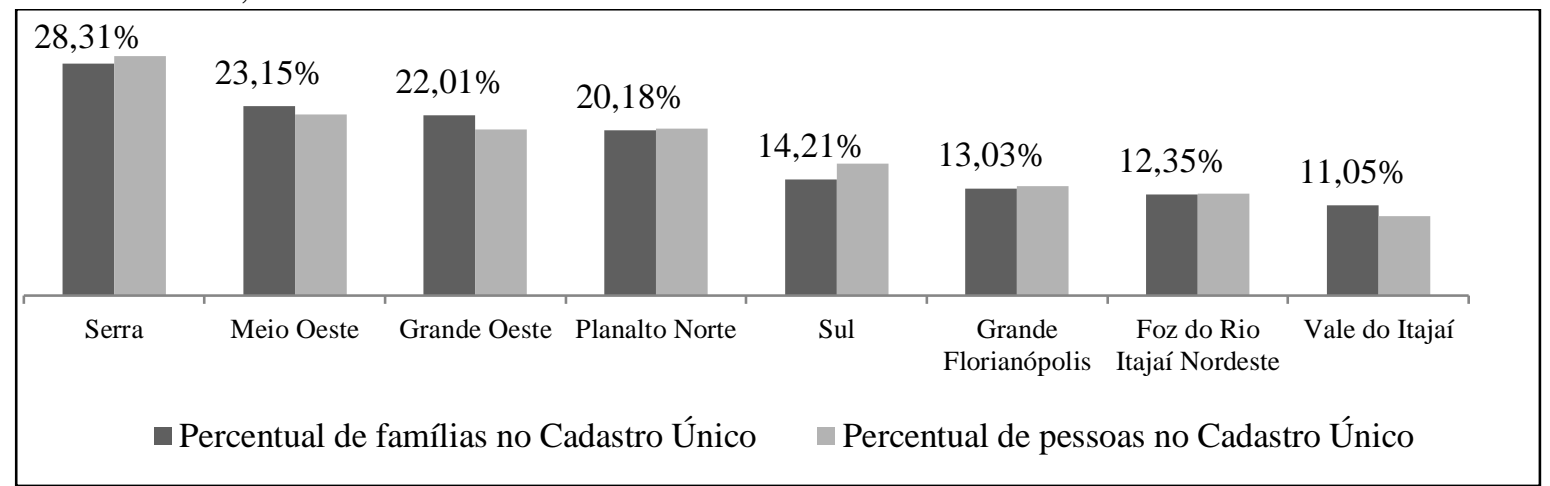

Fonte: CADUNICO - abri1/2018 
Em relação à distribuição das famílias por faixa de renda, as regiões da Serra Catarinense e do Planalto Norte apresentaram-se em evidência, segundo dados do Cadastro Único, conforme expressado na Tabela 3. Ambas apresentaram os maiores índices em relação à quantidade de famílias com renda per capita até meio salário mínimo, seguidas pelas regiões Sul e da Grande Florianópolis.

Segundo ilustra o Gráfico 2, as regiões do Grande Oeste e Meio Oeste, ao contrário do demonstrado no Gráfico 1, registraram os menores índices. Isso explica que, apesar do critério "baixa renda" para inscrição no Cadastro (meio salário mínimo per capita ou três salários mínimos de renda familiar total), existiam outras vulnerabilidades para inclusão das famílias, que não apenas a questão renda, evidenciando, nestas duas regiões, situações prioritárias que ultrapassam a pobreza.

Tabela 3: Total de famílias no cadastro único de acordo com a faixa da renda familiar per capita (números absolutos e percentuais) em Santa Catarina, abril/2018.

\begin{tabular}{lcccc}
\multicolumn{1}{c}{ Região } & Até $\mathrm{R} \$ 85,00$ & Entre R $\$ 85,00 \mathrm{e}$ & Entre R $\$ 170,00$ e $1 / 2 \mathrm{SM}$ & $\begin{array}{c}\text { Acima de } \\
1 / 2 \mathrm{SM}\end{array}$ \\
\hline Grande Oeste & & $\mathrm{R} \$ 170,00$ & 19.987 \\
& 12.552 & 8.001 & 15.175 & $35,88 \%$ \\
Meio Oeste & $22,53 \%$ & $14,36 \%$ & $27,24 \%$ & 18.671 \\
& 9.818 & 6.573 & 15.212 & $37,14 \%$ \\
Planalto Norte & $19,53 \%$ & $13,08 \%$ & $30,26 \%$ & 6.909 \\
& 5.367 & 4.383 & 8.548 & $27,41 \%$ \\
Foz do Rio Itajaí Nordeste & $21,30 \%$ & $17,39 \%$ & $33,92 \%$ & 25.569 \\
& 17.101 & 10.607 & 23.274 & $33,40 \%$ \\
Vale do Itajaí & $22,34 \%$ & $13,86 \%$ & $30,40 \%$ & 12.191 \\
& 7.733 & 4.332 & 10.129 & $35,46 \%$ \\
Grande Florianópolis & $22,49 \%$ & $12,6 \%$ & $29,46 \%$ & 17.905 \\
& 12.439 & 7.162 & 32.945 & $32,29 \%$ \\
Serra & $22,43 \%$ & $12,92 \%$ & $8.36 \%$ & 8.216 \\
& 8.779 & 4.245 & $29,52 \%$ & $27,27 \%$ \\
Sul & $29,14 \%$ & $14,09 \%$ & 16.118 & 14.873 \\
& 13.968 & 7.678 & $30,62 \%$ & $28,26 \%$ \\
\hline
\end{tabular}

Fonte: CADUNICO - abril/2018

Gráfico 2: Renda familiar per capita até meio salário mínimo em segundo o Cadastro único nas regiões socioassistenciais de Santa Catarina, abril/2018.

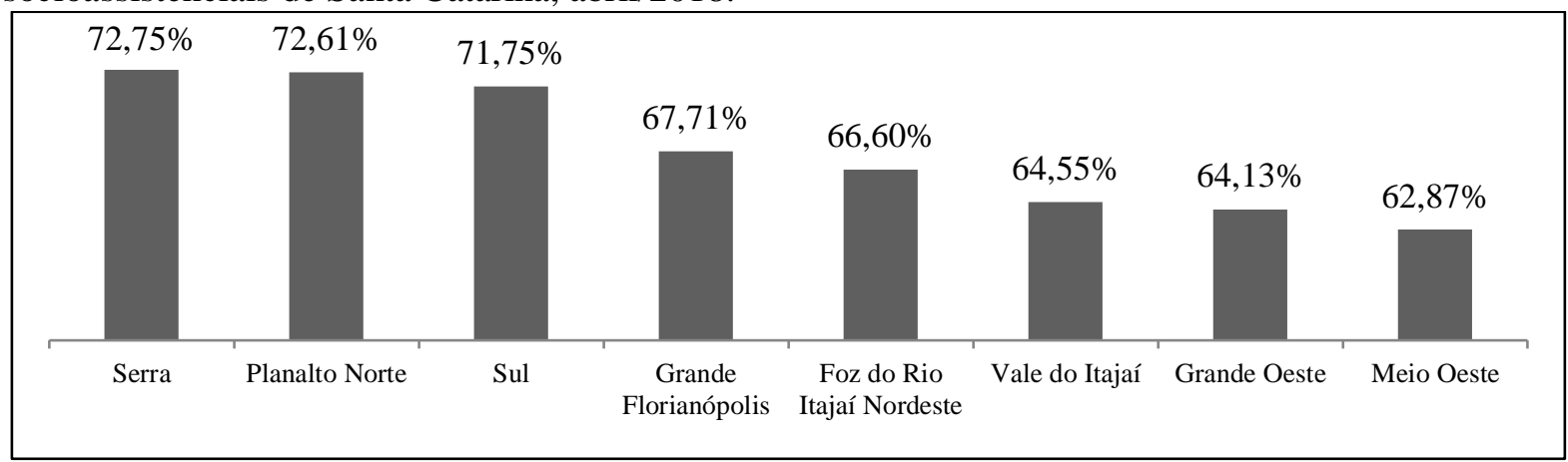

Fonte: CADUNICO - abril/2018 
O domicílio é considerado um local estruturalmente separado e independente, destinado a servir de habitação a uma ou mais pessoas, podendo ser particular ou coletivo, urbano ou rural. Nesse aspecto, a Tabela 4 reúne dados a respeito das condições de moradia em que as famílias residiam no período pesquisado. Os números demonstram que há diferentes fontes de inadequação da situação de moradia das famílias, e a identificação dos componentes mostra a existência de um quantitativo significativo de famílias que viviam em condições mais distantes de uma condição adequada de habitação.

Tabela 4: Características dos domicílios de acordo com as regiões socioassistenciais de Santa Catarina, abril/2018

\begin{tabular}{|c|c|c|c|c|c|c|c|c|c|}
\hline Caracterís & as do domicílio & $\begin{array}{l}\text { Grande } \\
\text { Oeste }\end{array}$ & $\begin{array}{l}\text { Meio } \\
\text { Oeste }\end{array}$ & $\begin{array}{l}\text { Planalto } \\
\text { Norte }\end{array}$ & $\begin{array}{c}\text { Foz do } \\
\text { Rio Itajaí } \\
\text { Nordeste } \\
\end{array}$ & $\begin{array}{l}\text { Vale do } \\
\text { Itajaí }\end{array}$ & $\begin{array}{l}\text { Grande } \\
\text { Fpolis }\end{array}$ & Serra & Sul \\
\hline \multirow{2}{*}{$\begin{array}{l}\text { Espécie de } \\
\text { domicílio }\end{array}$} & $\begin{array}{l}\text { Particular } \\
\text { Permanente }\end{array}$ & 93,82 & 96,87 & 98,61 & 97,64 & 97,94 & 95,54 & 98,62 & 97,88 \\
\hline & $\begin{array}{l}\text { Improvisado ou } \\
\text { Coletivo }\end{array}$ & 6,01 & 2,93 & 1,21 & 1,54 & 1,21 & 2,43 & 1,04 & 1,64 \\
\hline \multirow{2}{*}{$\begin{array}{l}\text { Água } \\
\text { canalizada }\end{array}$} & Sim & 89,35 & 96,97 & 94,54 & 96,31 & 95,58 & 93,25 & 96,15 & 95,15 \\
\hline & Não & 4,55 & 2,84 & 4,15 & 1,38 & 2,47 & 2,35 & 2,56 & 2,81 \\
\hline \multirow{2}{*}{$\begin{array}{l}\text { Forma de } \\
\text { abastecimento } \\
\text { de água }\end{array}$} & $\begin{array}{l}\text { Rede geral de } \\
\text { distribuição }\end{array}$ & 64,57 & 76,08 & 74,41 & 85,62 & 71,99 & 82,69 & 80,54 & 73,35 \\
\hline & $\begin{array}{l}\text { Poço, nascente ou } \\
\text { Cisterna }\end{array}$ & 29,33 & 20,89 & 24,27 & 12,07 & 26,05 & 12,91 & 18,16 & 24,60 \\
\hline \multirow{2}{*}{$\begin{array}{l}\text { Existência de } \\
\text { banheiro }\end{array}$} & Sim & 90,91 & 93,90 & 93,95 & 96,72 & 97,17 & 94,43 & 94,06 & 96,47 \\
\hline & Não & 3,00 & 3,08 & 4,74 & 0,97 & 0,88 & 1,16 & 4,65 & 1,49 \\
\hline \multirow{2}{*}{$\begin{array}{l}\text { Forma de } \\
\text { coleta do lixo }\end{array}$} & $\begin{array}{l}\text { Coletado direta ou } \\
\text { indiretamente }\end{array}$ & 68,19 & 83,81 & 83,59 & 97,13 & 89,89 & 94,51 & 88,53 & 94,48 \\
\hline & $\begin{array}{c}\text { Jogado em rio, mar, } \\
\text { terreno, queimado } \\
\text { ou enterrado } \\
\end{array}$ & 25,72 & 13,16 & 15,10 & 0,56 & 8,15 & 1,08 & 10,18 & 3,48 \\
\hline \multirow{2}{*}{$\begin{array}{l}\text { Tipo de } \\
\text { iluminação }\end{array}$} & $\begin{array}{l}\text { Elétrica (com ou } \\
\text { sem medidor) }\end{array}$ & 92,35 & 96,03 & 96,79 & 95,82 & 97,02 & 93,69 & 97,41 & 96,03 \\
\hline & $\begin{array}{l}\text { Óleo, querosene, } \\
\text { gás ou vela }\end{array}$ & 1,55 & 0,94 & 1,90 & 1,86 & 1,03 & 1,91 & 1,29 & 1,93 \\
\hline \multirow{2}{*}{$\begin{array}{l}\text { Situação do } \\
\text { domicílio }\end{array}$} & Urbano & 66,04 & 76,92 & 75,62 & 92,92 & 79,80 & 91,78 & 83,29 & 82,67 \\
\hline & Rural & 33,87 & 22,98 & 24,27 & 6,30 & 19,45 & 6,23 & 16,45 & 16,92 \\
\hline
\end{tabular}

\section{Fonte: CADUNICO - abril/2018}

Em termos práticos, a importância do saneamento básico está ligada à implantação de sistemas e modelos públicos que promovam o abastecimento de água, esgoto sanitário e destinação correta de lixo, com o objetivo de prevenção e controle de doenças, promoção de hábitos higiênicos e saudáveis, e melhorias da limpeza. 
No estado de Santa Catarina, muitos domicílios inseridos do CADUNICO apresentam-se sem água canalizada. As regiões do Grande Oeste e do Planalto Norte registraram mais de 4\% dos domicílios nessa situação. Essa situação se agravou ainda mais no Planalto Norte, que apresentava próximo de 2\% dos domicílios sem iluminação (junto com mesmo índice verificado nas regiões da Grande Florianópolis e Sul) e quase 5\% das moradias sem banheiro. Preocupante, também, mostrou-se a forma de abastecimento de água, em que mais de $20 \%$ das residências, na maioria das regiões, eram abastecidas por poço, nascente ou cisterna, não havendo, assim, rede geral de distribuição.

Impressiona, além disto, os números apresentados em relação à coleta de lixo, tendo a região da Grande Oeste registrado $25,72 \%$ do lixo sendo jogado ao ar livre ou enterrado, contra $0,56 \%$ na região da Foz do Rio Itajaí, nessa mesma situação. Números não desprezíveis foram registrados nas regiões Planalto Norte, Meio Oeste e Serrana, cujos percentuais de 15,10\%, 13,16\% e 10,18\%, respectivamente, do lixo foram jogados de forma inadequada, distante de outras regiões, como da Grande Florianópolis, $1,08 \%$.

Por seu turno, registram-se, de forma positiva, os percentuais de domicílios com iluminação. Em todas as regiões, os percentuais alcançaram patamar acima de $90 \%$, sendo que algumas, como as da Grande Florianópolis e do Vale do Itajaí, chegaram a superar 97\% dos domicílios utilizando energia elétrica, com ou sem medidor. Em contraponto, baixos foram os registros de outras formas de uso de energia - óleo, querosene, gás e vela.

A escolaridade é um dos principais caminhos para que os estratos de baixa renda obtenham uma melhor posição social, e consigam sair de uma situação de total carência para um patamar no qual obtenham um melhor nível de vida. Conforme dados da Tabela 5, algumas regiões do estado apresentaram situação deteriorada neste quesito, como a do Meio Oeste, cujo percentual foi de 9,78\%; da Serra Catarinense, com 9,50\%; e do Grande Oeste, com 9,25\% dos registros. Os números representando elevada preocupação variaram entre $6,5 \%$ e $9,8 \%$ das pessoas, registradas no Cadastro Único, que informaram não saber ler e nem escrever.

Tabela 5: Adultos analfabetos em Santa Catarina segundo regiões socioassistenciais,

Pessoas de 16 anos ou mais que não sabem ler ou escrever

\begin{tabular}{ccc}
\hline Grande Oeste & $9,25 \%$ & 10.231 \\
Meio Oeste & $9,78 \%$ & 9.488 \\
Planalto Norte & $6,59 \%$ & 3.455 \\
Foz do Rio Itajaí Nordeste & $6,56 \%$ & 9.376 \\
Vale do Itajaí & $7,36 \%$ & 4.924 \\
Grande Florianópolis & $6,74 \%$ & 6.906 \\
Serra Catarinense & $9,50 \%$ & 5.482 \\
Sul & $6,98 \%$ & 6.974 \\
TOTAL & & $\mathbf{5 6 . 8 3 6}$ \\
\hline
\end{tabular}

Fonte: CADUNICO - abril/2018 
Tabela 6: Pessoas que informam ter tido algum tipo de trabalhado nos últimos 12 meses segundo regiões socioassistenciais de Santa Catarina, abril/2018.

Trabalho nos últimos 12 meses

\begin{tabular}{cccccc}
\hline & Sim & Não & Sim & Não & TOTAL \\
Grande Oeste & $39,65 \%$ & $59,17 \%$ & 43.707 & 65.073 & 108.780 \\
Meio Oeste & $36,59 \%$ & $62,25 \%$ & 35.501 & 60.396 & 95.897 \\
Planalto Norte & $39,17 \%$ & $59,61 \%$ & 21.074 & 32.978 & 54.052 \\
Foz do Rio Itajaí Nordeste & $43,89 \%$ & $54,98 \%$ & 62.906 & 78.548 & 141.454 \\
Vale do Itajaí & $50,38 \%$ & $48,36 \%$ & 33.704 & 32.355 & 66.059 \\
Grande Florianópolis & $45,10 \%$ & $53,71 \%$ & 46.197 & 55.012 & 101.209 \\
Serra Catarinense & $33,61 \%$ & $65,27 \%$ & 19.332 & 38.029 & 57.361 \\
Sul & $38,11 \%$ & $60,63 \%$ & 38.068 & 60.556 & 98.624 \\
TOTAL & & & 300.489 & 422.947 & 723.436 \\
\hline
\end{tabular}

Fonte: CADUNICO - abril/2018

Conforme se pode observar na Tabela 6, mais da metade da população (acima de 16 anos) em todas as regiões, informou não ter nenhum tipo de trabalho nos últimos 12 meses. E, dentre aqueles que exerciam atividade remunerada, observa-se grande destaque para os trabalhadores que declararam realizar atividades por conta própria, de maneira autônoma ou "fazendo bicos", segundo se constata na Tabela 7.

Tabela 7: Tipo de Trabalho realizado segundo regiões socioassistenciais de Santa Catarina, abril/2018

\begin{tabular}{lcccccc}
\hline \multicolumn{1}{c}{ Região } & $\begin{array}{c}\text { Trabalhador } \\
\text { por conta } \\
\text { própria (bico, } \\
\text { autônomo) }\end{array}$ & $\begin{array}{c}\text { Trabalhador } \\
\text { tempoŕrio } \\
\text { em área } \\
\text { rural }\end{array}$ & $\begin{array}{c}\text { Empregado } \\
\text { sem carteira } \\
\text { de trabalho } \\
\text { assinada }\end{array}$ & $\begin{array}{c}\text { Empregado } \\
\text { com carteira } \\
\text { de trabalho } \\
\text { assinada }\end{array}$ & $\begin{array}{c}\text { Trabalhador } \\
\text { doméstico } \\
\text { sem carteira } \\
\text { de trabalho } \\
\text { assinada }\end{array}$ & $\begin{array}{c}\text { Trabalhador } \\
\text { doméstico } \\
\text { com carteira } \\
\text { de trabalho } \\
\text { assinada }\end{array}$ \\
\hline Foz do Rio Itajaí Nordeste & 23.292 & 287 & 2.190 & 19.093 & 1.461 & 443 \\
Grande Florianópolis & 18.037 & 413 & 1.654 & 16.288 & 920 & 638 \\
Grande Oeste & 18.977 & 5.666 & 2.019 & 11.503 & 884 & 458 \\
Meio Oeste & 12.586 & 2.426 & 1.628 & 12.103 & 1.248 & 383 \\
Planalto Norte & 8.643 & 1.394 & 399 & 5.197 & 537 & 202 \\
Serra Catarinense & 7.130 & 1.568 & 1.038 & 5.174 & 1.063 & 244 \\
Sul & 16.346 & 1.726 & 1.958 & 10.258 & 855 & 290 \\
Vale do Itajaí & 9.603 & 2.489 & 1.085 & 10.971 & 397 & 222 \\
TOTAL & 114.614 & 15.969 & 11.971 & 90.587 & 7.365 & 2.880 \\
\hline
\end{tabular}

Fonte: CADUNICO - abril/2018

A exigência do mercado impõe que o trabalhador tenha conhecimento de todas ou de parte das etapas do processo de produção $\mathrm{O}$ conhecimento obtido formalmente é um requerimento importante 
para ter participação ativa no processo de trabalho. Contudo, questiona-se: como parte não desprezível da população analfabeta ou analfabeta funcional pode ser "absorvida" pelo mercado de trabalho? $\mathrm{Na}$ busca de resposta, pode-se inferir que o grande contingente de desempregados nos centros urbanos é oriundo da condição de exclusão, que busca o mercado informal, sem nenhuma garantia social para sobreviver. A condição de analfabetismo é a principal geradora da vulnerabilidade social, visto que a baixa qualificação é um dos componentes para que outras mazelas sejam acrescidas.

\section{AÇÕES REALIZADAS PELA POLÍTICA DE ASSISTÊNCIA SOCIAL NO ENFRENTAMENTO DA VULNERABILIDADE EM SC}

Constituem o público usuário da Política de Assistência Social cidadãos e grupos que se encontram em situações de vulnerabilidade e riscos, como: famílias e indivíduos com perda ou fragilidade de vínculos de afetividade, pertencimento e sociabilidade; ciclos de vida; identidades estigmatizadas em termos étnico, cultural e sexual; desvantagem pessoal, resultante de deficiências; exclusão pela pobreza e, ou, no acesso às demais políticas públicas; uso de substâncias psicoativas; diferentes formas de violência advinda do núcleo familiar, grupos e indivíduos; inserção precária ou não inserção no mercado de trabalho formal e informal; estratégias e alternativas distintas de sobrevivência que podem representar riscos pessoal e social (BRASIL, 2004).

Com a aprovação da tipificação nacional de serviços socioassistenciais, em 2009 expresso no Quadro 01, a executora das ações de Proteção Social Básica passou a ser o Centro de Referência da Assistência Social - CRAS; e a executora das ações de Proteção Social Especial, o Centro de Referência Especializado de Assistência Social - CREAS.

A Proteção Social Básica tem como objetivo a prevenção, por meio do desenvolvimento de potencialidades, aquisições, e o fortalecimento de vínculos familiares e comunitários. Por seu turno, a Proteção Social Especial tem por finalidade proteger de situações de risco famílias e indivíduos cujos direitos tenham sido violados ou que já tenha ocorrido rompimento dos laços familiares e comunitários. Nesse sentido, o atendimento de proteção social básica é estruturado e organizado nos territórios onde se localizam as áreas de maior vulnerabilidade social, prestando serviços especializados e continuados a indivíduos e famílias com direitos violados, visando a atuação com as famílias e indivíduos em seu contexto comunitário, fortalecendo vínculos.

Outro serviço ofertado pelo CRAS é o Serviço de Proteção e Atendimento Integral à Família - PAIF. Esse serviço consiste em um trabalho social de caráter continuado, com famílias, com a finalidade de fortalecer a função protetiva, prevenir a ruptura dos seus vínculos, promover seu acesso e usufruto de direitos e contribuir na melhoria de qualidade de 
vida, trabalhando questões relativas à primeira infância, à adolescência, à juventude, ao envelhecimento e a deficiências, a fim de promover espaços para troca de experiências e reconhecimento de possibilidades (BRASIL, 2012).

As mudanças conjunturais nas famílias, como, por exemplo: uniões homoafetivas, guarda compartilhada, filhos legítimos e ilegítimos, desemprego e doenças, são alguns dos pontos a serem trabalhados pelos profissionais que atuam nos centros de referências e que devem sempre respeitar a heterogeneidade dos arranjos familiares. Nesse contexto, deve-se lembrar de que a matricial idade sociofamiliar é um dos principais conceitos da política de assistência.

O PAEFI é um serviço de atendimento especializado a famílias e indivíduos, prestando apoio, orientação e acompanhamento, especialmente, a famílias com um ou mais de seus membros em situação de ameaça ou violação de direitos. Nesse sentido, envolve atenções e orientações direcionadas para a promoção de direitos, a preservação e o fortalecimento de vínculos familiares, comunitários e sociais e para o fortalecimento da função protetiva das famílias diante do conjunto de condições que as submetem a situações de risco pessoal e social.

Quadro 1: Organização dos níveis de complexidade do SUAS

Serviços de Proteções Ofertados nos CRAS - Proteção Social Básica

Serviço de Proteção e Atendimento Integral à Família (PAIF)

Serviço de Convivência e Fortalecimento de Vínculos

Serviço de Proteção Social Básica no Domicílio para Pessoas com Deficiência e Idosas

Serviços de Proteções Ofertados nos CREAS - Proteção Social Especial - Média Complexidade

Serviço de Proteção e Atendimento Especializado a Famílias Indivíduos (PAEFI)

Serviço Especializado em Abordagem Social

Serviço de proteção social a adolescentes em cumprimento de medida socioeducativa de Liberdade Assistida (LA) e de Prestação de Serviços à Comunidade (PSC)

Serviço de Proteção Social Especial para Pessoas com Deficiência, Idosas e suas Famílias

Serviço Especializado para Pessoas em Situação de Rua

Proteção Social Especial Alta Complexidade

Serviço de Acolhimento Institucional

Serviço de Acolhimento em República

Serviço de Acolhimento em Família Acolhedora

Serviço de proteção em situações de calamidades públicas e de emergências

Fonte: Tipificação Nacional dos Serviços Socioassistenciais (2009)

Revista Desenvolvimento Socioeconômico em debate v.6 n.2 (2020) 
Nos termos apresentados, percebe-se que a Assistência Social progrediu como política pública, alcançando resultados eficazes e duradouros de proteção à família e aos cidadãos. Entretanto, é obrigação do Estado proporcionar condições do atendimento para além do atendimento, isto é, agenciar qualidade em face das demandas e necessidades sociais, tornandose provedora de proteção social.

Destacam-se, ainda, as ações de assessoria técnica qualificada prestada pelos técnicos estaduais aos municípios, de forma integrada, aos trabalhadores municipais do SUAS, para qualificação da gestão e dos serviços, programas, projetos e benefícios socioassistenciais, bem como, para o alcance das prioridades e metas pactuadas pelo governo federal. O trabalho realizado pelo Estado visa, também, contribuir na superação das dificuldades encontradas para implantação/implementação e organização do SUAS nos municípios, e fomentar os mecanismos de regulação e operacionalização do SUAS, visando, com tal exercício, fortalecer o comando único da Assistência Social.

\section{CONCLUSÃO}

Esta pesquisa, cujos resultados estão aqui apresentados, considerou as famílias vinculadas ao Cadastro Único e algumas variáveis que determinam a população vulnerável, tais como características dos domicílios, escolaridade e acesso ao trabalho. A análise dos resultados apontou que dentre as dimensões analisadas, as regiões do Oeste (Grande Oeste e Meio Oeste), Planalto Norte e Serra Catarinense apresentam índices de vulnerabilidade preocupantes. Nessas regiões, encontram-se pessoas com nível de renda baixo, nível educacional insuficiente, participação não desprezível em trabalho temporário e sem registro formal e residentes em domicílios com limitada infraestrutura básica. Em contrapartida, as regiões do Foz do Itajaí/Nordeste e Vale do Itajaí apresentam quadros vulneráveis não tão expressivos, seguidos pelas regiões da Grande Florianópolis e Sul, com números que oscilam de acordo com a dimensão.

Tratando-se de um público do Cadastro Único, esses dados são consideráveis e preocupam. Mais ainda, levando-se em consideração tratar-se de um estado com elevado IDH, figurando em $3^{\circ}$ lugar do país, superado apenas pelo Distrito Federal e o estado de São Paulo. O grande desnível social em nível regional em Santa Catarina não é compatível com uma economia considerada o $6^{\circ}$ maior PIB - produto interno bruto - indicador importante que expressa a riqueza produzida em setores econômicos agricultura, indústria e comércio/serviços -, dentre os 26 estados federativos e um distrito federal.

Nesse sentido, se faz necessário avaliar as políticas de desenvolvimento regional, além das demandas dos segmentos e territórios mais vulneráveis, sendo vários os desafios na construção de uma rede efetiva de promoção e proteção social. É necessário, portanto, conhecer a realidade do município e 
nela atuar, priorizando as situações de maior vulnerabilidade, dada a complexidade dos processos sociais de desproteção social e a extensão de necessidades e demandas a serem atendidas. Desse modo, a implantação do CRAS é uma estratégia de descentralização e hierarquização de serviços de assistência social e, portanto, elemento essencial do processo de planejamento territorial e da política de assistência social do município.

A configuração de uma política pública territorialmente, articulada deve ser baseada no reconhecimento das capacidades coletivas desses locais, espaços de vida e vivência que são, com características políticas, econômicas e culturais. Certamente, há que se despertar para a capacidade de compreender a importância dessa tarefa para o fortalecimento e a consolidação do SUAS e, uma vez mais, dar respostas concretas aos desafios postos no momento presente, para que, em futuro breve, outros desafios possam ser enfrentados com resultados positivo.

\section{REFERÊNCIAS}

BRASIL. Constituição (1988). Constituição da República Federativa do Brasil: promulgada em 5 de outubro de 1988.

Lei Orgânica da Assistência Social. Brasília, DF, Senado, 1993.

Política Nacional de Assistência Social. Ministério de Desenvolvimento Social e Combate à fome. Secretaria Nacional de Assistência Social. Brasília: 2004

Norma Operacional Básica NOB SUAS. Ministério de Desenvolvimento Social e Combate à fome. Conselho Nacional de Assistência Social - CNAS. Brasília: 2005. 95p.

. CapacitaSUAS Vol.3 (2008). Planos de Assistência Social: diretrizes para elaboração.

Ministério do Desenvolvimento Social e Combate à Fome, Instituto de Estudos Especiais da Pontifícia Universidade Católica de São Paulo - 1 ed - Brasília: MDS, 2008.

Orientações Técnicas: Centro de Referência de Assistência Social CRAS. Brasília:

Ministério do Desenvolvimento Social e Combate à Fome, 2009. 72p.

Tipificação Nacional de Serviços Socioassistenciais. Ministério do Desenvolvimento Social e Combate à Fome. Secretaria Nacional de Assistência Social. Brasília: MDS, 2009

Norma Operacional Básica NOB SUAS. Ministério de Desenvolvimento Social e Combate à fome. Conselho Nacional de Assistência Social - CNAS. Brasília: 2012. 43p.

Orientações Técnicas sobre o PAIF. Volume 02. Brasília: Ministério do Desenvolvimento Social e Combate à Fome, 2012. 112p.

Capacita SUAS Volume 3: SUAS: Garantia do Caráter Público da Política de Assistência Social, Brasília: Brasília: Ministério de Desenvolvimento Social e Combate à Fome. 2013. 
Cadastro Único - CADÚNICO. Ministério de Desenvolvimento Social e Combate à Fome Disponível em <https://aplicacoes.mds.gov.br/sagi/cecad>. Acesso em nov. 2018.

BRAUDEL, F. Civilização material, economia e capitalismo: séculos XV-XVIII, volume 3. O tempo do mundo. São Paulo: Martins Fontes, 1996.

BRESSER-PEREIRA, L. C. Globalização e estado-nação. Texto para discussão, 160. Escola de Economia de São Paulo, FGV, 2007.

BRESSER-PEREIRA, L. C. A reforma do estado dos anos 90: lógica e mecanismos de controle. Brasília: Ministério da Administração Federal e Reforma do Estado, 58 p. (Cadernos MARE da reforma do estado; v. 1), 1997.

BUSS, P. M. Globalização, pobreza e saúde. Ciência saúde coletiva, v.12, ed.6, p.1575-1589, 2007.

CHANG, H-J. The economic theory of the development state. In: WOO-CUMUNGS, M (eds.). The developmental state. New York: Cornell University Press. 1999.

CHANG, H-J. An institutionalist perspective on the role of the State - towards an institutionalist political economy. In.: L. Burlamaqui, A. Castro and H-J. Chang (eds.), Institutions and the Role of the State. Aldershot: Edward Elgar, 2000.

COUTO, B. R.; YAZBEK, M. C.; RAICHELIS, R. A política nacional de assistência social e o SUAS: apresentando e problematizando fundamentos e conceitos. In: COUTO, Berenice Rojas et al. (Org.). O sistema único de assistência social no Brasil: uma realidade em movimento. São Paulo: Cortez, 2010. p. 32-65.

DIAS, T. Uma experiência de governança pública: a relação entre Estado e sociedade desenvolvida no governo do Estado de Santa Catarina a partir da implantação das Secretarias de Desenvolvimento Regional. Tese: Universidade Federal de Santa Catarina (UFSC), Florianópolis, 2012.

DIAS, T.; CARIO, S. A. F. Sociedade, desenvolvimento e o papel estratégico do Estado: uma reflexão sobre o surgimento da governança pública. Ensaios FEE [Impresso], v. 35, p. 337-362, 2014.

FONSECA, P. C. D. Desenvolvimentismo: a construção do conceito. In: CALIXTRE, A. B.; BIANCARELli, A. M.; CINTRA, M. A. C. (Org.). Presente e Futuro do Desenvolvimento Brasileiro. 1 ed. Brasília, 2014, vol., p. 29-78. 2014.

GERSCHENKRON, A. Economic backwardness in historical perspective. Cambridge, Massachusetts: Harvard University Press, 1962.

IGLESIAS, E. El papel del Estado y los paradigmas económicos. Revista de la CEPAL, Santiago de Chile, n. 90, p.7-15, dez. 2006. 
INSTITUTO BRASILEIRO DE GEOGRAFIA E ESTATÍSTICA (IBGE). Censo Brasileiro de 2010. Rio de Janeiro: IBGE, 2018

MARICATO, E. Brasil, cidades: alternativas para a crise urbana. $2^{\mathrm{a}}$ ed. Petrópolis: vozes, 2001, $204 \mathrm{p}$.

MESTRINER, M. L. O Estado entre a filantropia e a assistência social. 2. ed. São Paulo: Cortez, 2001

PNUD - PROGRAMA DAS NAÇÕES UNIDAS PARA O DESENVOLVIMENTO; IPEA INSTITUTO DE PESQUISA ECONÔMICA E APLICADA; FUNDAÇÃO JOÃO PINHEIRO. Atlas de desenvolvimento humano do Brasil de 2013. Disponível em: http://atlasbrasil.org.br/2013/. Acesso em junho de 2018.

SANTOS, M. A natureza do espaço: Técnica e tempo. Razão e emoção. São Paulo: Hucitec, 1996. 392p.

SANTOS, M. O espaço do cidadão. São Paulo: Nobel, 2000. 176p.

SANTOS, M. Território globalização e fragmentação. São Paulo: Hucitec, 1994. 172p.

SILVA, T. G. M. A Vigilância Social na Política de Assistência Social: Análise dos aspectos conceituais e operacionais no âmbito municipal. Dissertação de Mestrado em pós-graduação em Serviço Social e Política Social da Universidade Estadual de Londrina. Londrina, 2012.

SPOSATI, A. Contribuição para a Construção do Sistema Único de Assistência Social - SUAS. Revista Serviço Social e Sociedade, n. ${ }^{\circ}$ 78, 2004

TORRES, H. G; MARQUES, E; FERREIRA, M. P; BITAR, S. Pobreza e espaço: padrões de segregação em São Paulo. Estudos avançados. v.17, ed.47, p.97- 128, 2003.

ZYSMAN, J. How institutions create historically rooted trajectories of growth. Industrial and Corporate Change. v. 3, n. 1, p. 243-283, 1994.

Recebido: 23/03/2020

Aceito: $14 / 09 / 2020$

Publicado: outubro de 2020. 